\title{
Gender-specific liver aging and magnetic resonance imaging
}

\author{
Yî Xiáng J. Wáng^ \\ Department of Imaging and Interventional Radiology, Faculty of Medicine, The Chinese University of Hong Kong, New Territories, Hong Kong \\ SAR, China
}

Correspondence to: Dr. Yì Xiáng J. Wáng. Department of Imaging and Interventional Radiology, Faculty of Medicine, The Chinese University of Hong Kong, New Territories, Hong Kong SAR, China. Email: yixiang_wang@cuhk.edu.hk.

\begin{abstract}
The number of imaging studies performed on elderly individuals will increase in the next several decades. It is important to understand normal age-related changes in the structural and functional imaging appearance of the liver. This article highlights a number of liver aging aspects which are particularly relevant to magnetic resonance imaging (MRI). Physiology of aging liver is associated with a reduction in size, in perfusion, and in function. Pulsed echo-Doppler showed substantial reduction of portal flow in elderly subjects, particularly those after the age of 75 years old. An MRI biomarker diffusion derived vessel density (DDVD) demonstrated that liver microperfusion volume in healthy females starts to decrease even before menopause age. Liver fat content and iron content increase with aging, and the change is more substantial in women after menopause. Adult men have higher liver fat and iron contents than women from the start and change less during aging. Nonalcoholic fatty liver disease (NAFLD) is very common among assumed healthy subjects. There is a male predominance of NAFLD from the paediatric population up to fifth decade of life in adults. After the age of 60 years, women overtake their male counterparts in prevalence of NAFLD. Higher liver fat leads to decreased apparent diffusion coefficient (ADC) and intravoxel incoherent

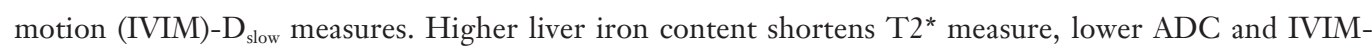
$\mathrm{D}_{\text {slow }}$ measures, increases imaging noises and decreases liver visibility. Young women have high liver T1rho value and then decrease substantially, while liver T1rho in men remains relatively unchanged with aging. In positron emission tomography (PET) studies, aging is associated with an increase of both liver fluorine-18fluorodeoxyglucose maximum standard uptake and mean standard uptake values.
\end{abstract}

Keywords: Magnetic resonance imaging (MRI); liver; vessel density; aging; diffusion; fat; iron; positron emission tomography (PET); fluorodeoxyglucose (FDG)

Submitted Mar 08, 2021. Accepted for publication Apr 15, 2021.

doi: 10.21037/qims-21-227

View this article at: http://dx.doi.org/10.21037/qims-21-227

The number of imaging studies performed on elderly individuals will increase in the next several decades. It is important to understand normal age-related changes in the structural and functional imaging appearance of the liver. Healthy aging of organs is a well-studied topic and covered in many imaging literatures. Aging of some organs such as brain, spine, hip/knee joints etc. can be well noted on imaging (1-3). For example, intervertebral disc nucleus pulposus appears high signal in young subjects, while typically appear grey/low signal in older subjects. A grey/low signal disc nucleus pulposus would suggest degeneration if seen among young subjects, but considered part of normal aging in elderly subjects (3). Quantitative $\mathrm{T} 2$ and T1rho relaxation times of the disc nucleus pulposus show apparent reduction with healthy aging (4). However, the aging of liver has got less attention among radiology

\footnotetext{
^ ORCID: 0000-0001-5697-0717.
} 


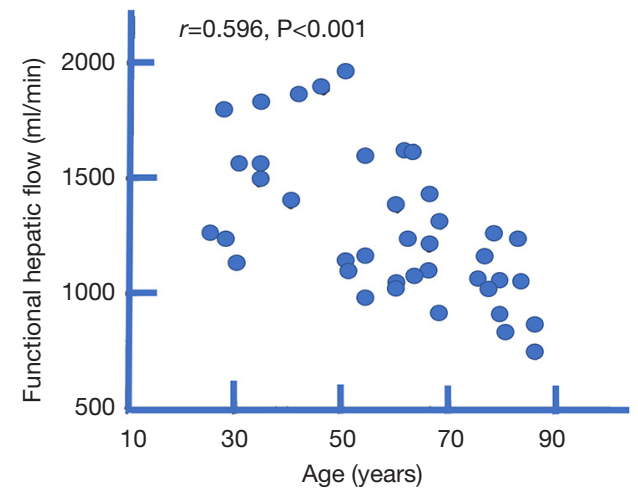

Figure 1 The relationship between aging and functional hepatic flow measured by the hepatic clearance of D-sorbitol. The reduction in hepatic blood flow is particularly evidential after the age of 75 years. Adapted from reference (16).

community. This article highlights a number of liver aging aspects which are particularly relevant to MRI.

\section{Physiology of liver aging: reduction in size, in perfusion, and in function}

Physiology of liver aging has been well studied. Macroscopically the liver undergoes 'brown atrophy' with old age. The brown appearance is secondary to the accumulation of pigmented waste products within hepatocytes. Hepatocytes in elderly subjects contain denser body compartments, such as secondary lysosomes and lipofuscin, than do hepatocytes in younger subjects (5). Lipofuscin accumulation is associated with chronic oxidative stress and a failure to degrade damaged and denatured proteins (6). At the cellular level, hepatocytes grow in size but decrease in numbers with age (7). Mitochondria of hepatocytes increase in size but decrease in overall number with age (8).

Post-mortem studies suggest that there is an age-related fall in liver weight, which has been well confirmed by in-vivo imaging studies (9-11). It is estimated that, compared with those under 40 years of age, individuals above the age of 65 years have $25-35 \%$ lower liver volume (12).

Old age can be associated with a reduction in hepatic blood flow of about $35-40 \%$. This has been documented using a variety of technical methods (13-16). Zoli et al. (16) studied hepatic blood flow in 40 normal subjects in four age groups ( $<45,45-60,61-75$ and $>75$ years). Each group consisted of 10 subjects (five men and five women). Total hepatic flow was measured by pulsed echo-Doppler, as the sum of portal and hepatic artery blood flow. Functional hepatic flow was measured by the hepatic clearance of D-sorbitol. Both total hepatic flow and functional hepatic flow significantly decreased with age, particularly in subjects over 75 years (Figure 1). Zoli et al. noted that portal vein size did not change with age, varying from 1.16 to $1.03 \mathrm{~cm}$, while echo-Doppler measured portal blood velocity and flow decreased from the age of 45 years onwards. Hepatic artery velocity and flow did not change significantly in various age groups, although a mild increase (possibly compensatory) was observed between 45 and 75 years. The hepatic artery flow constituted $17 \%$ of total hepatic flow in younger subjects; after the age of 45 years, it rose to about $25 \%$, the proportion then remaining stable. In the oldest group ( $>75$ years) total hepatic flow decreased by $30 \%$.

Fiel et al. (14) reported an increasing arteriolar wall thickness and a decrease in luminal diameter of liver arterioles with aging (Figure 2). The thickening of the sinusoidal endothelial lining with collagen and fall in endothelial cell fenestrations can impair blood flow through liver sinusoids and hepatic perfusion, and reduce oxygendependent hepatocyte function (17).

Using an magnetic resonance imaging (MRI) biomarker DDVD (diffusion derived vessel density) $(18,19)$, we demonstrated liver microperfusion volume in healthy females starts to decrease even before menopause age (Figure 3) (20). In suggesting that DDVD reduction started during the middle age at least for females, our in-vivo imaging results concur with the histological study of Fiel et al. (14). DDVD data also show young women have higher liver microperfusion volume than young men (20).

The liver has a pivotal role in the regulation of the metabolism of carbohydrates, proteins and lipids. While most of the routine clinical tests of liver function do not change significantly with aging, the synthesis of proteins, lipid and glucose decreases with age. The index of routine clinical liver function tests to correlate with age is bilirubin (21). Bile flow and bile salt formation are reduced by about $50 \%$ in elderly subjects (12). There is a significant negative correlation between plasma albumin concentration and age (22). Dong et al. (23) reported age was associated with modest decreases in albumin and $\gamma$-glutamyl transpeptidase concentrations, and increases in bilirubin concentration, after adjustments for sex, alcohol use, and components of the metabolic syndrome. It has been estimated that serum albumin decreases by $0.54 \mathrm{~g} / \mathrm{L}$ per decade (24). Aged liver is associated with a reduction of galactose elimination, a reduction in binding of radiolabelled galactosyl-albumin, 

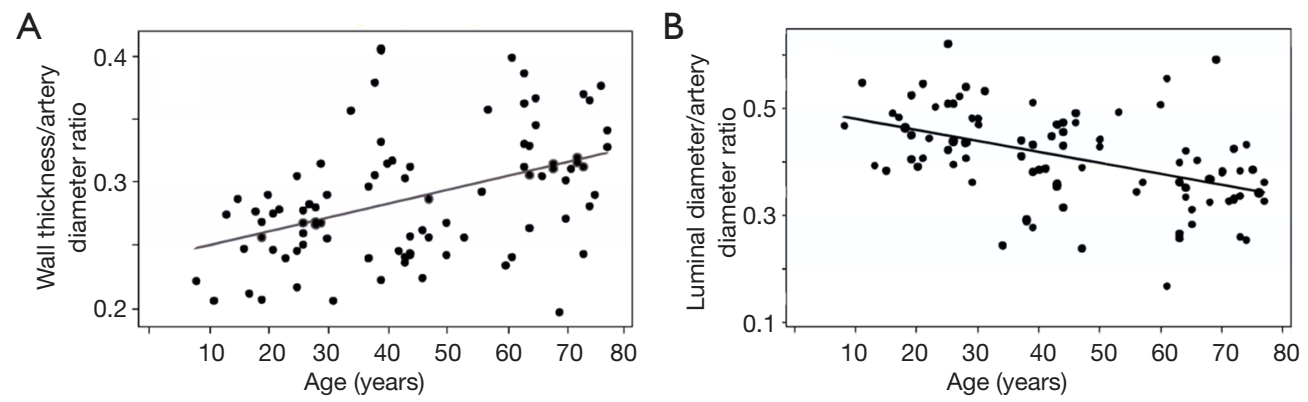

Figure 2 The relationship of increasing ratio of the wall thickness to cross sectional hepatic arteriolar diameter with increasing age (A), and a decreasing ratio of luminal diameter to cross sectional hepatic arteriolar diameter with increasing age (B). Adapted from (14).
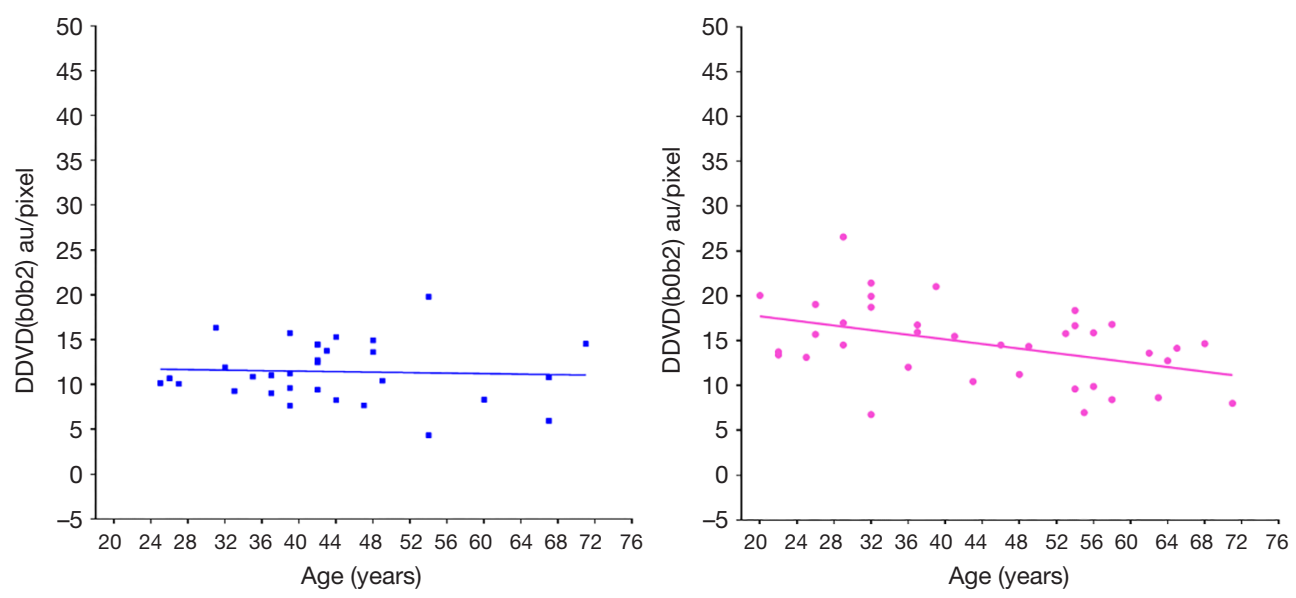

Figure 3 Liver DDVD measurement (y-axis) of healthy volunteers and their ages ( $\mathrm{x}$-axis). The results of men (left, $\mathrm{n}=31$ ) do not show an apparent trend, while the results of women (right, $\mathrm{n}=37$ ) show a trend of decrease as age increases $(\mathrm{P}=0.01)$. Note male subjects do not have sufficient representation for $>60$ years old group in this study. DDVD(b0b2) refers to signal difference between $b=0 v s . b=2 \mathrm{~s} / \mathrm{mm}^{2}$ images. DDVD, diffusion derived vessel density. Reproduced with permission from (20).

and reduction of urea synthesis $(10,25,26)$.

Among elderly subjects, there is a more limited liver function reserve. Complex liver functions are less responsive to challenges, leading to a higher disease susceptibility. A change in drug clearance with aging is an important factor for the high prevalence of adverse drug reactions among the elderly. In a survey of more than 1,200 elderly patients admitted to an acute care hospital, Hurwitz (27) found that the incidence of adverse drug reactions more than tripled beyond the age of 70 years. Well-known changes in the clearance of drugs that undergo hepatic metabolism are attributed to age-associated alterations in hepatic enzyme activity and to reduced liver size and hepatic blood flow. It is recommended that, for the elderly, drugs which are metabolized and excreted by the liver should be used at a starting dose which is $30-40 \%$ smaller than the average dose used in middle-aged adults (15).

\section{Increase of liver fat content with aging}

Efficient fat metabolism is paramount to the maintenance of systemic nutritional homeostasis. The ability of mammals to store and draw on fat reserves has been a driving force throughout evolution in an environment with intermittent nutrient availability. In a typical adult, lipids comprise $80 \%$ of energy reserves. With the improved nutrition in modern society, overstore of fat in liver has been an issue. In general populations, liver fat content increases with age.

Ulbrich et al. (28) studied 80 healthy Swiss volunteers aged between 20 and 62 years $(10$ men/10 women per 

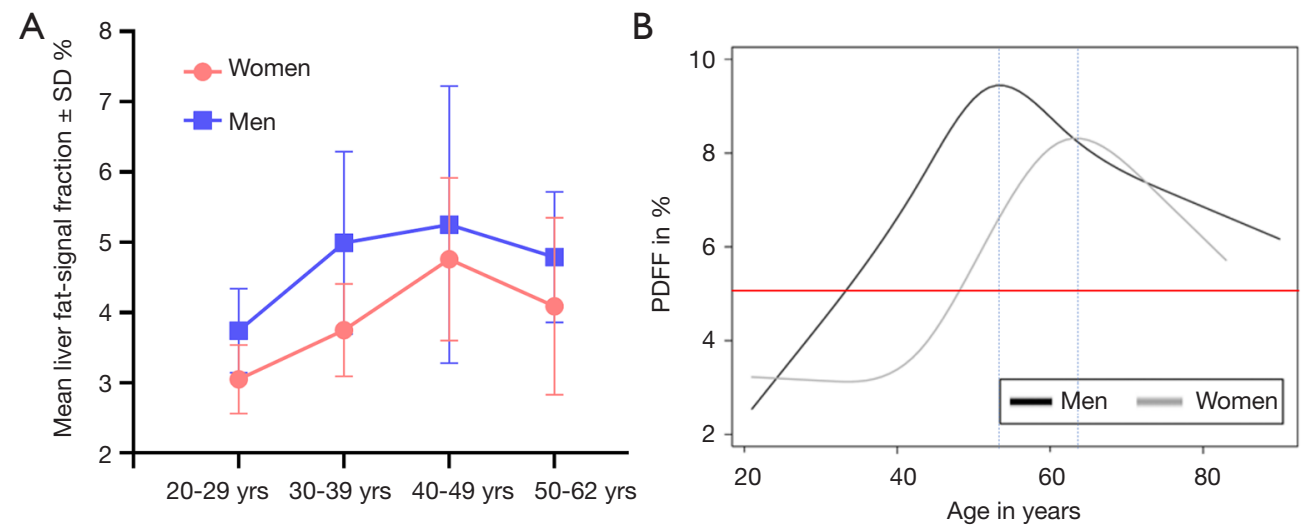

Figure 4 Gender-specific relationships between age and liver fat content. (A) Gender-specific relationships between age and liver signal fraction among 40 Swiss men and 40 Swiss women. Adapted from (28). (B) Gender-specific relationships between age and liver fat content (PDFF) among 1,225 German men and 1,336 German women. Adapted from (29).
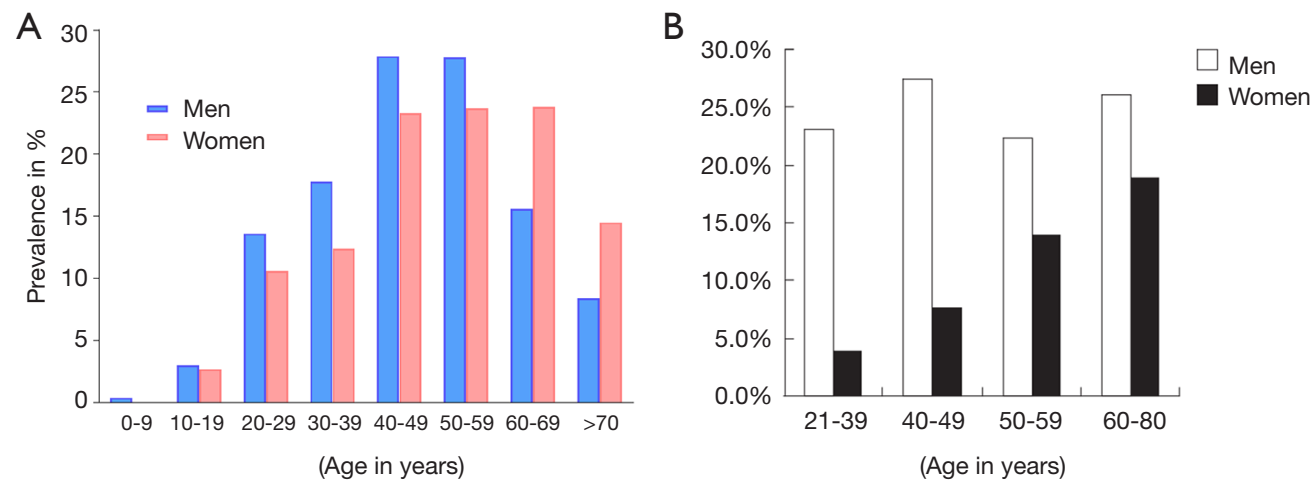

Figure 5 Age- and gender-specific prevalence of ultrasonography estimated nonalcoholic fatty liver disease (NAFLD). (A) Prevalence of NAFLD among 1,271 Japanese men and 1,303 Japanese women. Adapted from (33). (B) Prevalence of NAFLD among 1,829 Japanese women and 2,572 Japanese men. Adapted from (32).

decade) with normal body-mass index. It was reported that fat signal fraction (FSF) ranged from $2.77 \%$ to $10.06 \%$ (mean $4.69 \% \pm 1.38 \%$ ) for men, and ranged from $1.80 \%$ to $7.56 \%$ (mean $3.91 \% \pm 1.10 \%$ ) for women. Liver fat content was higher in men than in women and peaked in the fifth decade for both men and women (Figure 4A). Kühn et al. (29) quantified liver proton density fat fraction (PDFF) in a population-based study of 2,561 participants $(1,336$ women; median age, 52 years; 25 th and 75 th quartiles, 42 and 62 years), and reported the median PDFF was $3.9 \%$ (range, $0.6-41.5 \%)$. In men, liver-fat content increased continuously between age 20 and 50 years; in women, liver fat content increased began 20 years later, extending from 40 to 65 years (Figure $4 B$ ). In the Dallas Heart Study where hepatic fat content was assessed in 2,287 participants using MR spectroscopy, Szczepaniak et al. (30) reported a median liver fat content of $4.7 \%$ (25\% and $75 \%$ quantiles, $2.7 \%$ and $8.6 \%)$.

Nonalcoholic fatty liver disease (NAFLD) is common worldwide. The mildest form of NAFLD is simple steatosis, characterised by intrahepatic fat (triglyceride) accumulation alone ( $\geq 5 \%$ of liver weight). Currently, the diagnosis of NAFLD is based on detection of hepatic steatosis by liver biopsy or imaging, exclusion of other liver diseases, particularly alcohol and hepatitis B/C. In nonalcoholic steatohepatitis (NASH), hepatic necroinflammatory changes are present and a characteristic perisinusoidal pattern of liver fibrosis is common. $\mathrm{Up}$ to 
$25 \%$ of NAFLD patients have NASH. The true prevalence of NASH, the most clinically relevant subset of patients with NAFLD, is difficult to establish because this is a histologic diagnosis.

NAFLD is common among assumed healthy population. Epidemiological studies suggest male predominance of NAFLD from the paediatric population up to fifth decade of life in adults. After the age of 60 years, females overtake their male counterparts in prevalence of NAFLD, with an age and gender distribution resembling that of cardiovascular disease (31-33) (Figure 5). In the US, an estimated one-third of the population has NAFLD and approximately $2-5 \%$ have NASH (34). A study in predominantly middle-aged American employees or outpatients (without known liver disease) found that the prevalence of steatosis by ultrasonography was $47 \%$; in this study, NASH was confirmed histologically in $12 \%$ of the total cohort or $30 \%$ of the ultrasound positive subgroup (35). One ultrasonographic study of 26,527 Chinese subjects (age: $47.41 \pm 10.13$ years, range: 20 to 70 years) receiving medical health check-ups shows NAFLD prevalence was $31 \%$ in men and $16 \%$ in women (36). NAFLD prevalence is rapidly increasing in China (37).

Liver fat content also has implications in routine imaging. Meier et al. reported the CT attenuation of adult liver decrease significantly with increasing age (11). It has been well known that liver steatosis induces MR diffusion measure reduction (38-42). Liver fat increases the size of hepatocytes, and the increased size of liver cells is associated with a smaller extracellular space and this may lead to a restriction of molecular motion of water molecules. Echo planar image acquisition commonly uses spatial-spectral pulses for fat suppression (i.e., water-only excitation). Water excitation pulses have a spectral bandwidth centered on the water peak (located at $4.7 \mathrm{ppm}$ ), while the NMR spectrum of triglycerides in liver fat has several peaks (between 4.2 and $5.3 \mathrm{ppm}$ ) close to the water peak (43). Water excitation pulses, even in the absence of $\mathrm{B}_{0}$ inhomogeneities will excite about $9 \%$ of the triglyceride proton magnetization (44). Thus, lipid signal peaks near water are often incompletely suppressed by the fat suppression techniques; and the measured diffusivity may incorporate the diffusion constant of lipid, which is much slower than water, with higher $b$-values leading to even lower observed diffusion coefficient $(43,44)$.

\section{Increase of liver iron content with aging}

In healthy subjects there are iron storage depots located for the most part in the liver, spleen, and bone marrow. Iron is stored in the liver as iron (III) oxyhydroxide particles in the form of ferritin and hemosiderin. Hemosiderin is a degradation product of ferritin particles that is insoluble and is more likely to aggregate. States of negative iron balance occur when the body requirements for iron exceed the amounts being absorbed from the gastrointestinal tract. This may be the result of physiological events such as growth spurts, menstruation and pregnancy, or of any pathological state that causes blood loss. In healthy subjects without diet iron deficiency, liver iron concentration rises sharply in men toward the end of the adolescent growth spurt in the late teens and reached maximum before 40 years old. After 40 years old, liver iron level remains constant or slightly increases until approximately the age of 70 years, after which it may declines (45-48). In women, liver iron concentration remains relatively low until after the fourth decade of life, after which they exhibit a steep rise. The relative low mean value among women in the 21 - to 40 -year-old group is associated with a high iron demand of menstruation during the childbearing age. Maximum levels observed in women after menopause are approximately two thirds of those for men of comparable age (45-51).

Liver iron can particularly affect $\mathrm{T} 2$ * imaging and diffusion weighted imaging (DWI). $\mathrm{R} 2^{*}\left(1 / \mathrm{T} 2^{*}\right)$ is commonly used to evaluate hepatic iron concentration $(38,52,53)$, with higher iron concentration shortens T2* (and increases R2*). Schwenzer et al. (54) assessed 1.5 Telsa $\mathrm{T}^{*}$ relaxation time of liver in a cohort of 129 healthy German subjects ( 85 women, 44 men; age range: 20 to 70 years, mean age, $47.9 \pm 11.4$ years), and reported a mean liver tissue $\mathrm{T}^{*}$ value of $28.1 \pm 7.1 \mathrm{~ms}$ (range, $13.6-45.9 \mathrm{~ms}$ ), which corresponds to a mean R2* of $35.6 \mathrm{~s}^{-1}$. There was a significantly higher hepatic $\mathrm{T}^{*}{ }^{*}$ values for women $(14.7-45.9$ $\mathrm{ms}$ ) than for men (13.6-43.1 ms, $\mathrm{P}<0.01)$. 'Iron overload' was observed in approximately $7 \%$ of participants. A statistically significant correlation of $\mathrm{T}^{*}$ decrease over age was seen (for men, Pearson $r=-0.30, \mathrm{P}<0.05$; for women, $r=-0.46, \mathrm{P}<0.0001)$.

In a study of 2,561 German participants (1,336 women; median age: 52 years), Kühn et al. (29) quantified liver iron content with $\mathrm{R} 2^{*}$ at 1.5 Telsa, and study participants were stratified as follows: none iron overload $\left(\mathrm{R} 2^{*}, \leq 41.0 \mathrm{~s}^{-1}\right)$, mild iron overload $\left(\mathrm{R} 2^{*},>41 \mathrm{~s}^{-1}\right)$, moderate iron overload $\left(\mathrm{R} 2^{*},>62.5 \mathrm{~s}^{-1}\right)$, high iron overload $\left(\mathrm{R} 2^{*}:>70.1 \mathrm{~s}^{-1}\right)$. Median R2* was $34.4 \mathrm{~s}^{-1}$ (range, 14.0-311.8 $\mathrm{s}^{-1}$ ). It was shown that men had $20.9 \%$ higher 'liver iron' content compared with women. 'Iron overload' was observed in $17.4 \%$ of 
participants, with male participants of $27.2 \%$ and female participants of $9.0 \%$. The severity distribution was mild: $14.7 \%$, moderate: $0.8 \%$, and high content: $2.0 \%$. A combination of hepatic steatosis and 'liver iron' overload was observed in $9.3 \%$ of the study participants. Liver iron content was mainly associated with mean serum corpuscular haemoglobin in men and in women. In women, age was also associated with liver iron.

However, it should be noted that the measured liver R2* value is confounded by the presence of hepatic steatosis. In a study of patients with NAFLD/NASH, Bashir et al. (55) reported that liver PDFF was positively correlated with $\mathrm{R} 2 *$ at both $1.5 \mathrm{~T}$ and at $3 \mathrm{~T}$. They suggested that for patient population with NAFLD/NASH, R2* is not a reliable technique for quantifying liver iron when high level liver iron deposition is relatively rare. It is suggested that intrahepatocellular triglyceride droplets can cause susceptibility effects. Although individual iron particles have much greater susceptibility effects than individual similarly sized fat droplets, the amount of iron encountered in the NAFLD/NASH population tends to have a narrow range from none to mild, while the range of fat content is broad. In cases with high liver fat content, liver fat has a greater impact on measured $\mathrm{R} 2$ * values than liver iron.

With DWI, iron deposition can create both macroscopic sub-voxel magnetic field inhomogeneities that leads to errors in ADC (apparent diffusion coefficient) estimation. Sener (56) reported magnetic field inhomogeneities can lead to a reduction of ADC measure in the brain. Higher liver iron content is also associated with lower liver ADC measure. Chandarana et al. (57) studied this effect in phantom and in liver using a 1.5 Tesla magnet. In phantoms, there was a decrease in ADC ( $b$-values: 0/50/500 s/ $\mathrm{mm}^{2}$ ) and $\mathrm{T}^{*}$ with increasing iron concentration. Patients with hepatic siderosis had significantly lower signal-to-noise ratio and ADC ( $b$-values: $50 / 500 \mathrm{~s} / \mathrm{mm}^{2}$ ) compared with patients without siderosis. There was a significant correlation between liver $\mathrm{T}^{*}$ and ADC $(r=0.83)$. Signal-to-noise ratio at $b=50$ and $500 \mathrm{~s} / \mathrm{mm}^{2}$ and $\mathrm{ADC}$ had a significant negative correlation with pathologic iron grade ( $r=-0.67$ to 0.77 ). Bülow et al. (58) studied the relationship between ADC (b-values: 50/400/800 s/ $\mathrm{mm}^{2}$ ) and liver iron content in subjects without liver fibrosis and without steatosis (total 33 cases, among them 11 cases had an increased liver iron content) and demonstrated a moderate negative correlation between $\mathrm{ADC}$ values and iron load.

With a study in 34 men and 52 women, Metens et al. (59) reported that normal liver parenchyma visibility on DWI and ADC measure ( $b$-values: $150,600,1,000 \mathrm{~s} / \mathrm{mm}^{2}$ ) are influenced by age and iron content. Normal DWI liver visibility negatively correlates with normal range iron content markers. Liver visibility was better in young women but degrades with age in both genders. The liver average ADC was negatively correlated with age, and the values were higher in women $\left(0.785 \pm 147 \times 10^{-3} \mathrm{~mm}^{2} / \mathrm{s}\right)$ than in men $\left(0.742 \pm 103 \times 10^{-3} \mathrm{~mm}^{2} / \mathrm{s} ; \mathrm{P}=0.027\right)$. Liver T2* (at 3 Tesla) in men $(19.3 \pm 4.2 \mathrm{~ms}$, range $13.8-28.6 \mathrm{~ms})$ was statistically significantly lower than that in women $(22.7 \pm 4.6 \mathrm{~ms}$, range: 13.2-31.0 ms; $\mathrm{P}=0.016)$. In women, liver $\mathrm{T} 2 *$ decreased statistically significantly with age. Metens et al. (59) noted an underestimation of the parenchymal ADC in patients with low liver visibility together with an increased uncertainty of the ADC value. Therefore, while the signal of the normal liver parenchyma is often used as a reference to establish the DWI signal of the hepatic lesions, the normal liver signal intensity can vary according to the age and gender iron content dependence.

Recently, we performed a study with 30 men and 36 women and demonstrated a trend of IVIM (intravoxel incoherent motion)- $\mathrm{D}_{\text {slow }}$ decreasing related to healthy

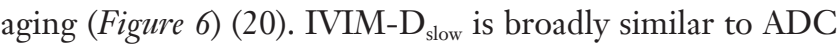
measure without very low $b$-values.

The liver iron change with aging is also expected to be relevant in liver susceptibility imaging (quantitative susceptibility mapping) $(60,61)$.

\section{Decrease of liver T1rho measure in women with aging}

T1rho (T1 $\rho)$ relaxation time describes spin-lattice relaxation in the rotation frame at the presence of an external radiofrequency pulse in the transverse plane. It has been demonstrated that T1rho elongation is a sensitive biomarker for collagen deposition and thus a sensitive biomarker for liver fibrosis (62-64). To translate liver T1rho MRI into clinical practice, it is important to know the physiological liver T1rho measure in healthy subjects. We conducted a healthy volunteer study in 62 women (mean age: 38.9 years; range: $18-75$ years) and 34 men (mean age: 44.7 years; range: $24-80$ years). Female liver T1rho value ranged between 35.07 and $51.97 \mathrm{~ms}$ and showed an age-dependent decrease, with younger women having a higher measurement (65). The male liver T1rho value ranged between 34.94 and $43.39 \mathrm{~ms}$, with no evidential age dependence (Figure 7).

The underlying cause for such liver T1rho dynamics and 

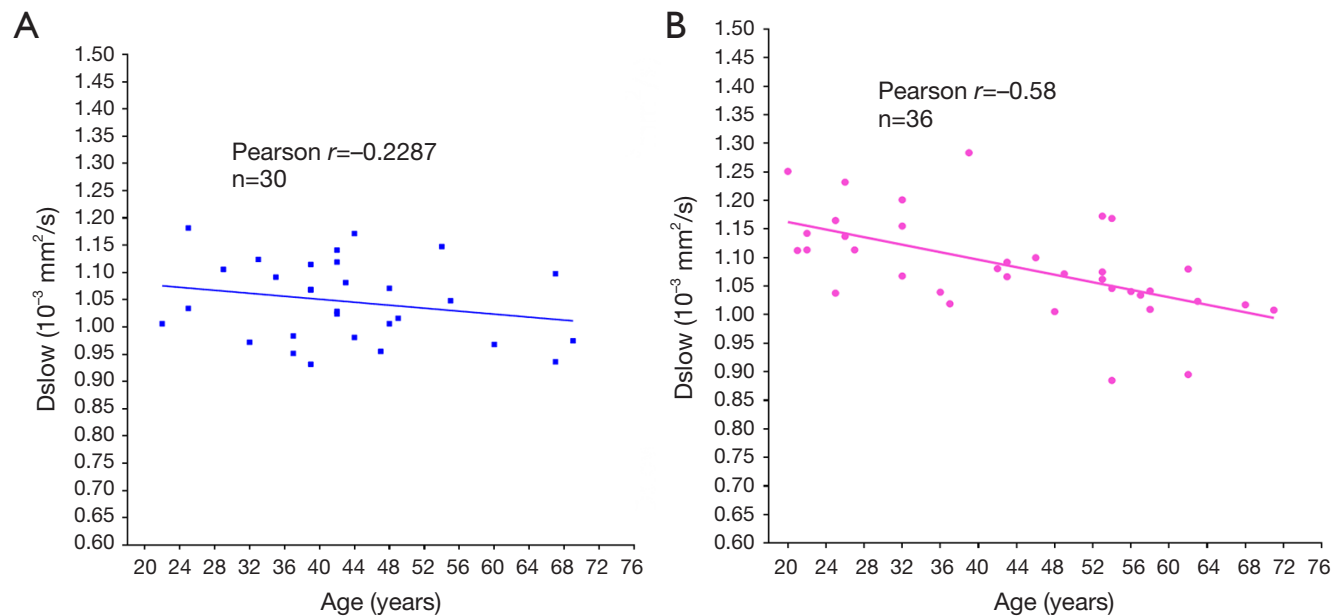

Figure 6 The relationship between age and liver IVIM-D $\mathrm{D}_{\text {slow }}$ in healthy men (A) and women (B). Aging is associated with a general reduction of $\mathrm{D}_{\text {slow }}$, which is more apparent in women than in men. Overall young men have lower $\mathrm{D}_{\text {slow }}$ measure than young women, which could be due to that, compared with young women, young men generally have higher liver iron content, higher liver fat content, and lower blood perfusion volume. IVIM, intravoxel incoherent motion. Reproduced with permission from (20).
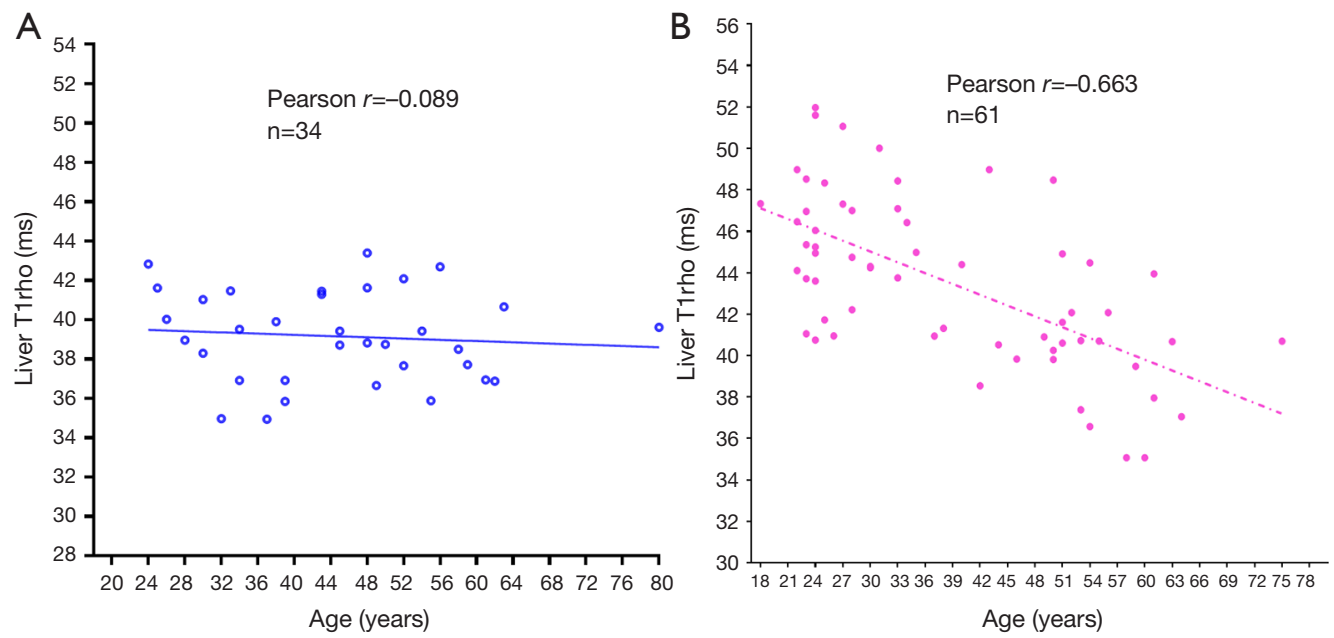

Figure 7 The relationship between liver T1rho and age in healthy men (A) and women (B). A very substantial age-related reduction of liver T1rho measure is noted in women, but not apparent in men. Reproduced with permission from (65).

male female difference remains unknown. Compared with other MRI techniques such as $\mathrm{T}^{*}$ and diffusion imaging, T1rho may be relatively insensitive to physiological liver iron deposition (66). For subjects without apparent liver steatosis (i.e., $<5 \%$ fat content) and when fat suppression technique is applied, the contributed from liver fat to T1rho shortening is expected to be limited relative to the physiological variation of liver T1rho. Our previous analysis suggests that $10 \%$ additional liver fat contribute to
$1.55 \mathrm{~ms}$ liver T1rho shortening (67). Also, for both women and men, no association was seen between body mass index and liver T1rho (65). Therefore, we do not expect the liver T1rho dynamics is largely affected by liver iron and fat contents. One may think there would be age- and genderassociated collagen content variation in healthy aging liver. Till now, studies on this topic remain limited, and most studies were conducted on animal models. Mild fibrosis is a hallmark of the aging of various organs, including the 

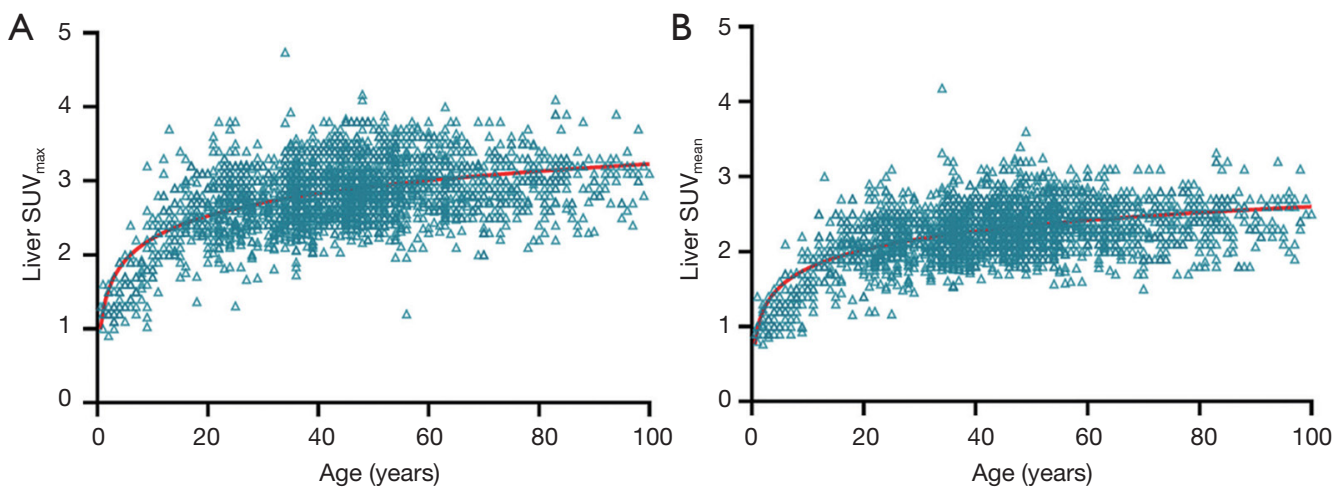

Figure 8 Age-related changes of standardized uptake values (SUV) in the liver, with data of 2,526 subjects (1,436 men and 1,090 women). (A) liver maximum SUV; (B) liver mean SUV. Reproduced with permission from (72).

liver, which reflects increased deposition of the extracellular matrix. Grasedyck et al. (68) reported that although the collagen content of the human liver declines after the growth period of youth, the amount of the connective tissue then remains nearly constant throughout adulthood and into old age. In an aging rat model, Gagliano et al. (69) reported that interstitial collagen accumulated significantly in the oldest animals, mainly in the periportal area. An increase of collagen content in aging livers does not explain the reduction of liver T1rho.

\section{Increase of liver fluorodeoxyglucose (FDG) uptake with aging}

Since aged livers are associated with less blood perfusion and decreased hepatocyte number, one would expect aged livers have less fluorine-18-FDG uptake. However, it has been well documented that aging is associated with an increase of both liver maximum standard uptake value (SUVmax) and liver mean standard uptake value (SUVmean) on FDG positron emission tomography (PET) imaging (11,70-72). Cao et al. (72) studied a total of 2,526 subjects underwent FDG PET/CT examinations, and reported that liver SUVmax and SUVmean rise rapidly until the age of 20 and then show a slow upward trend without reaching a plateau (Figure 8). Meier et al. (11) noted that, the metabolic activity of the liver increases significantly with age in adults, and the overall metabolic volumetric product, a measure that takes into account an organ's volume and metabolism by multiplying the hepatic volume by the hepatic mean SUV, trend slightly upward with age. While aging is associated with an increase of liver FDG uptake, Lin et al. (70) reported that there is no statistically significant relationship between sex, hepatitis $\mathrm{B}$ virus and hepatitis $\mathrm{C}$ virus infection status, and SUVmax or SUVmean of the liver.

The causes for this significant increase in liver metabolism in aging liver have not been fully elucidated (72). It may reflect cumulative inflammatory changes secondary to increasing duration of exposure to processing of toxins by liver (71).

PET/MRI scanners have been introduced in clinical use. In PET imaging, liver FDG uptake is commonly used as the reference standard for diagnosis, therapy assessment, and quality control. Radiologists should be familiar with this age-related increased liver FDG uptake in elderly population. This high physiological background FDG uptake may reduce diagnostic sensitivity and accuracy for detecting malignant lesions and result in false negative findings in the liver on PET imaging.

In conclusion, aging livers are associated with a reduction in organ volume and blood perfusion (in total and in per volume tissue), an increase in fat and iron deposition, and an increase in FDG uptake. With liver aging, quantitative MR metrics show lower DDVD, shortened T2*, lower ADC, lower IVIM- $\mathrm{D}_{\text {slow }}$, and in women lower T1rho. These changes are generally more apparent in women due to women's physiological cycle of menstruation, pregnancy, and later menopause. These aspects should be considered during interpreting daily clinical images as well as in designing research. On the other hand, the aging process can vary greatly from person to person. Furthermore, subclinical diseases in apparently normal persons, smoking habits, nutritional differences and other factors will provide 
'noises' and contribute to the wide variability in aging process.

\section{Acknowledgments}

Funding: The writing-up of this paper was partially supported by a Hong Kong GRF grant (Project No. 14109218).

\section{Footnote}

Conflicts of Interest: The author has completed the ICMJE uniform disclosure form (available at http://dx.doi. org/10.21037/qims-21-227). The author serves as the Editor-In-Chief of Quantitative Imaging in Medicine and Surgery. The author has no conflicts of interest to declare.

Open Access Statement: This is an Open Access article distributed in accordance with the Creative Commons Attribution-NonCommercial-NoDerivs 4.0 International License (CC BY-NC-ND 4.0), which permits the noncommercial replication and distribution of the article with the strict proviso that no changes or edits are made and the original work is properly cited (including links to both the formal publication through the relevant DOI and the license). See: https://creativecommons.org/licenses/by-nc-nd/4.0/.

\section{References}

1. Ketonen LM. Neuroimaging of the aging brain. Neurol Clin 1998;16:581-98.

2. Hayashi D, Roemer FW, Guermazi A. Imaging for osteoarthritis. Ann Phys Rehabil Med 2016;59:161-9.

3. Adams MA, Roughley PJ. What is intervertebral disc degeneration, and what causes it? Spine (Phila Pa 1976) 2006;31:2151-61.

4. Wang YX, Griffith JF, Leung JC, Yuan J. Age related reduction of T1rho and T2 magnetic resonance relaxation times of lumbar intervertebral disc. Quant Imaging Med Surg 2014;4:259-64.

5. Schmucker DL, Sachs H. Quantifying dense bodies and lipofuscin during aging: a morphologist's perspective. Arch Gerontol Geriatr 2002;34:249-61.

6. Jung T, Bader N, Grune T. Lipofuscin: formation, distribution, and metabolic consequences. Ann N Y Acad Sci 2007;1119:97-111.

7. Watanabe T, Tanaka Y. Age-related alterations in the size of human hepatocytes. A study of mononuclear and binucleate cells. Virchows Arch B Cell Pathol Incl Mol Pathol 1982;39:9-20.

8. Tauchi H, Sato T. Age changes in size and number of mitochondria of human hepatic cells. J Gerontol 1968;23:454-61.

9. Niederau C, Sonnenberg A, Müller JE, Erckenbrecht JF, Scholten T, Fritsch WP. Sonographic measurements of the normal liver, spleen, pancreas, and portal vein. Radiology 1983;149:537-40.

10. Wakabayashi H, Nishiyama Y, Ushiyama T, Maeba T, Maeta $\mathrm{H}$. Evaluation of the effect of age on functional hepatocyte mass and liver blood flow, using liver scintigraphy in preoperative estimation from surgical patients: comparison with CT volumetry. J Surg Res 2002;106:246-53.

11. Meier JM, Alavi A, Iruvuri S, Alzeair S, Parker R, Houseni M, Hernandez-Pampaloni M, Mong A, Torigian DA. Assessment of age-related changes in abdominal organ structure and function with computed tomography and positron emission tomography. Semin Nucl Med 2007;37:154-72.

12. Le Couteur DG, McLean AJ: The aging liver. Drug clearance and an oxygen diffusion barrier hypothesis. Clin Pharmacokinet 1998;34:359-73.

13. Wynne HA, Cope LH, Mutch E, Rawlins MD, Woodhouse KW, James OF. The effect of age upon liver volume and apparent liver blood flow in healthy man. Hepatology 1989;9:297-301.

14. Fiel MI, Deniz K, Elmali F, Schiano TD. Increasing hepatic arteriole wall thickness and decreased luminal diameter occur with increasing age in normal livers. J Hepatol 2011;55:582-6.

15. Zeeh J, Platt D. The aging liver: structural and functional changes and their consequences for drug treatment in old age. Gerontology 2002;48:121-7.

16. Zoli M, Magalotti D, Bianchi G, Gueli C, Orlandini C, Grimaldi M, Marchesini G. Total and functional hepatic blood flow decrease in parallel with ageing. Age Ageing 1999;28:29-33.

17. McLean AJ, Cogger VC, Chong GC, Warren A, Markus AM, Dahlstrom JE, Le Couteur DG. Agerelated pseudocapillarization of the human liver. J Pathol 2003;200:112-7.

18. Wáng YX. Living tissue intravoxel incoherent motion (IVIM) diffusion $\mathrm{MR}$ analysis without $\mathrm{b}=0$ image: an example for liver fibrosis evaluation. Quant Imaging Med Surg 2019;9:127-33.

19. Xiao BH, Huang H, Wang LF, Qiu SW, Guo SW, Wang 
YX. Diffusion MRI Derived per Area Vessel Density as a Surrogate Biomarker for Detecting Viral Hepatitis B-Induced Liver Fibrosis: A Proof-of-Concept Study. SLAS Technol 2020;25:474-83.

20. Huang H, Zheng CJ, Wang LF, Che-Nordin N, Wáng YXJ. Age and gender dependence of liver diffusion parameters and the possibility that intravoxel incoherent motion modeling of the perfusion component is constrained by the diffusion component. NMR Biomed 2021;34:e4449.

21. Tietz NW, Shuey DF, Wekstein DR. Laboratory values in fit aging individuals-sexagenarians through centenarians. Clin Chem 1992;38:1167-85.

22. Greenblatt DJ. Reduced serum albumin concentration in the elderly: a report from the Boston Collaborative Drug Surveillance Program. J Am Geriatr Soc 1979;27:20-2.

23. Dong MH, Bettencourt R, Barrett-Connor E, Loomba R. Alanine aminotransferase decreases with age: the Rancho Bernardo Study. PLoS One 2010;5:e14254.

24. Campion EW, deLabry LO, Glynn RJ. The effect of age on serum albumin in healthy males: report from the Normative Aging Study. J Gerontol 1988;43:M18-20.

25. Marchesini G, Bua V, Brunori A, Bianchi G, Pisi P, Fabbri A, Zoli M, Pisi E. Galactose elimination capacity and liver volume in aging man. Hepatology 1988;8:1079-83.

26. Marchesini G, Bianchi GP, Fabbri A, Lolli R, Bugianesi E, Zoli M, Pisi E. Synthesis of urea after a protein-rich meal in normal man in relation to ageing. Age Ageing 1990;19:4-10.

27. Hurwitz N. Predisposing factors in adverse reactions to drugs. Br Med J 1969;1:536-9.

28. Ulbrich EJ, Fischer MA, Manoliu A, Marcon M, Luechinger R, Nanz D, Reiner CS. Age- and Gender Dependent Liver Fat Content in a Healthy Normal BMI Population as Quantified by Fat-Water Separating DIXON MR Imaging. PLoS One 2015;10:e0141691.

29. Kühn JP, Meffert P, Heske C, Kromrey ML, Schmidt CO, Mensel B, Völzke H, Lerch MM, Hernando D, Mayerle J, Reeder SB. Prevalence of Fatty Liver Disease and Hepatic Iron Overload in a Northeastern German Population by Using Quantitative MR Imaging. Radiology 2017;284:706-16.

30. Szczepaniak LS, Nurenberg P, Leonard D, Browning JD, Reingold JS, Grundy S, Hobbs HH, Dobbins RL. Magnetic resonance spectroscopy to measure hepatic triglyceride content: prevalence of hepatic steatosis in the general population. Am J Physiol Endocrinol Metab 2005;288:E462-8.
31. Gan L, Chitturi S, Farrell GC. Mechanisms and Implications of Age-Related Changes in the Liver: Nonalcoholic Fatty Liver Disease in the Elderly. Curr Gerontol Geriatr Res 2011;2011:831536.

32. Hamaguchi M, Kojima T, Ohbora A, Takeda N, Fukui M, Kato T. Aging is a risk factor of nonalcoholic fatty liver disease in premenopausal women. World J Gastroenterol 2012;18:237-43.

33. Nomura H, Kashiwagi S, Hayashi J, Kajiyama W, Tani S, Goto M. Prevalence of fatty liver in a general population of Okinawa, Japan. Jpn J Med 1988;27:142-9.

34. Vernon G, Baranova A, Younossi ZM. Systematic review: the epidemiology and natural history of non-alcoholic fatty liver disease and non-alcoholic steatohepatitis in adults. Aliment Pharmacol Ther 2011;34:274-85.

35. Williams CD, Stengel J, Asike MI, Torres DM, Shaw J, Contreras M, Landt CL, Harrison SA. Prevalence of nonalcoholic fatty liver disease and nonalcoholic steatohepatitis among a largely middle-aged population utilizing ultrasound and liver biopsy: a prospective study. Gastroenterology 2011;140:124-31.

36. Chen ZW, Chen LY, Dai HL, Chen JH, Fang LZ. Relationship between alanine aminotransferase levels and metabolic syndrome in nonalcoholic fatty liver disease. J Zhejiang Univ Sci B 2008;9:616-22.

37. Zhou F, Zhou J, Wang W, Zhang XJ, Ji YX, Zhang P, She ZG, Zhu L, Cai J, Li H. Unexpected Rapid Increase in the Burden of NAFLD in China From 2008 to 2018: A Systematic Review and Meta-Analysis. Hepatology 2019;70:1119-33.

38. Wáng YXJ, Wang X, Wu P, Wang Y, Chen W, Chen H, Li $\mathrm{J}$. Topics on quantitative liver magnetic resonance imaging. Quant Imaging Med Surg 2019;9:1840-90.

39. Leitão HS, Doblas S, d'Assignies G, Garteiser P, Daire JL, Paradis V, Geraldes CF, Vilgrain V, Van Beers BE. Fat deposition decreases diffusion parameters at MRI: a study in phantoms and patients with liver steatosis. Eur Radiol 2013;23:461-7.

40. Anderson SW, Soto JA, Milch HN, Ozonoff A, O'Brien M, Hamilton JA, Jara HJ. Effect of disease progression on liver apparent diffusion coefficient values in a murine model of NASH at 11.7 Tesla MRI. J Magn Reson Imaging 2011;33:882-8.

41. Murphy P, Hooker J, Ang B, Wolfson T, Gamst A, Bydder M, Middleton M, Peterson M, Behling C, Loomba R, Sirlin C. Associations between histologic features of nonalcoholic fatty liver disease (NAFLD) and quantitative diffusion-weighted MRI measurements in adults. J Magn 
Reson Imaging 2015;41:1629-38.

42. Manning P, Murphy P, Wang K, Hooker J, Wolfson T, Middleton MS, Newton KP, Behling C, Awai HI, Durelle J, Paiz MN, Angeles JE, De La Pena D, McCutchan JA, Schwimmer JB, Sirlin CB. Liver histology and diffusionweighted MRI in children with nonalcoholic fatty liver disease: A MAGNET study. J Magn Reson Imaging 2017;46:1149-58.

43. Hamilton G, Yokoo T, Bydder M, Cruite I, Schroeder ME, Sirlin CB, Middleton MS. In vivo characterization of the liver fat (1)H MR spectrum. NMR Biomed 2011;24:784-90.

44. Hansmann J, Hernando D, Reeder SB. Fat confounds the observed apparent diffusion coefficient in patients with hepatic steatosis. Magn Reson Med 2013;69:545-52.

45. Zacharski LR, Ornstein DL, Woloshin S, Schwartz LM. Association of age, sex, and race with body iron stores in adults: analysis of NHANES III data. Am Heart J 2000;140:98-104.

46. Charlton RW, Hawkins DM, Mavor WO, Bothwell TH. Hepatic storage iron concentrations in different population groups. Am J Clin Nutr 1970;23:358-70.

47. Gautier du Défaix H, Puente R, Vidal B, Pérez E, Vidal H. Liver storage iron in normal population of Cuba. Am J Clin Nutr 1980;33:133-6.

48. Wang JL, Shaw NS. Iron status of the Taiwanese elderly: the prevalence of iron deficiency and elevated iron stores. Asia Pac J Clin Nutr 2005;14:278-84.

49. Sturgeon P, Shoden A. Total liver storage iron in normal populations of the USA. Am J Clin Nutr 1971;24:469-74.

50. Celada A, Herreros V, De Castro S. Liver iron storage in Spanish aging population. Am J Clin Nutr 1980;33:2662-4.

51. Weinfeld A, Lundin P, Lundvall O. Significance for the diagnosis of iron overload of histochemical and chemical iron in the liver of control subjects. J Clin Pathol 1968;21:35-40.

52. Wood JC, Enriquez C, Ghugre N, Tyzka JM, Carson S, Nelson MD, Coates TD. MRI R2 and R2* mapping accurately estimates hepatic iron concentration in transfusion-dependent thalassemia and sickle cell disease patients. Blood 2005;106:1460-5.

53. Hankins JS, McCarville MB, Loeffler RB, Smeltzer MP, Onciu M, Hoffer FA, Li CS, Wang WC, Ware RE, Hillenbrand CM. R2* magnetic resonance imaging of the liver in patients with iron overload. Blood 2009; 113:4853-5.

54. Schwenzer NF, Machann J, Haap MM, Martirosian P, Schraml C, Liebig G, Stefan N, Häring HU, Claussen
CD, Fritsche A, Schick F. T2* relaxometry in liver, pancreas, and spleen in a healthy cohort of one hundred twenty-nine subjects-correlation with age, gender, and serum ferritin. Invest Radiol 2008;43:854-60.

55. Bashir MR, Wolfson T, Gamst AC, Fowler KJ, Ohliger M, Shah SN, et al. Hepatic R2* is more strongly associated with proton density fat fraction than histologic liver iron scores in patients with nonalcoholic fatty liver disease. J Magn Reson Imaging 2019;49:1456-66.

56. Sener RN. Echo-planar and gradient-echo diffusion MRI of normal brain iron in the globus pallidus. Clin Imaging 2002;26:371-4.

57. Chandarana H, Do RK, Mussi TC, Jensen JH, Hajdu CH, Babb JS, Taouli B. The effect of liver iron deposition on hepatic apparent diffusion coefficient values in cirrhosis. AJR Am J Roentgenol 2012;199:803-8.

58. Bülow R, Mensel B, Meffert P, Hernando D, Evert M, Kühn JP. Diffusion-weighted magnetic resonance imaging for staging liver fibrosis is less reliable in the presence of fat and iron. Eur Radiol 2013;23:1281-7.

59. Metens T, Ferraresi KF, Farchione A, Moreno C, Bali MA, Matos C. Normal hepatic parenchyma visibility and ADC quantification on diffusion-weighted MRI at $3 \mathrm{~T}$ : influence of age, gender, and iron content. Eur Radiol 2014;24:3123-33.

60. Sharma SD, Hernando D, Horng DE, Reeder SB. Quantitative susceptibility mapping in the abdomen as an imaging biomarker of hepatic iron overload. Magn Reson Med 2015;74:673-83.

61. Liu S, Buch S, Chen Y, Choi HS, Dai Y, Habib C, Hu J, Jung JY, Luo Y, Utriainen D, Wang M, Wu D, Xia S, Haacke EM. Susceptibility-weighted imaging: current status and future directions. NMR Biomed 2017;30:10.1002/nbm.3552.

62. Wang YX, Yuan J, Chu ES, Go MY, Huang H, Ahuja AT, Sung JJ, Yu J. T1rho MR imaging is sensitive to evaluate liver fibrosis: an experimental study in a rat biliary duct ligation model. Radiology 2011;259:712-9.

63. Zhao F, Zhou N, Wang JL, Zhou H, Zou LQ, Zhong WX, He J, Zheng CJ, Yan SX, Wáng YXJ. Collagen deposition in the liver is strongly and positively associated T1rho elongation while fat deposition is associated with T1rho shortening: an experimental study of methionine and choline-deficient (MCD) diet rat model. Quant Imaging Med Surg 2020;10:2307-21.

64. Allkemper T, Sagmeister F, Cicinnati V, Beckebaum S, Kooijman H, Kanthak C, Stehling C, Heindel W. Evaluation of fibrotic liver disease with whole-liver 
T1 $\rho$ MR imaging: a feasibility study at 1.5 T. Radiology 2014;271:408-15.

65. Wáng YXJ, Deng M, Lin J, Kwok AWL, Liu EKW, Chen W. Age- and Gender-Associated Liver Physiological T1rho Dynamics Demonstrated with a Clinically Applicable Single-Breathhold Acquisition. SLAS Technol 2018;23:179-87.

66. Wáng YXJ. Physiological variation of liver iron concentration may not be dominantly responsible for the liver T1rho variations associated with age and gender. Quant Imaging Med Surg 2021;11:1668-73.

67. Zhao F, Zhou N, Wang X, Wang JL, Zhong WX, Deng M, Zheng CJ, He J, Yan SX, Wáng YXJ. T1rho shortening effect of fat in liver steatosis after fat suppression: approximate estimation in a methionine and cholinedeficient (MCD) diet rat model. Quant Imaging Med Surg 2021;11:870-5.

68. Grasedyck K, Jahnke M, Friedrich O, Schulz D, Lindner

Cite this article as: Wáng YXJ. Gender-specific liver aging and magnetic resonance imaging. Quant Imaging Med Surg 2021;11(7):2893-2904. doi: 10.21037/qims-21-227
J. Aging of liver: morphological and biochemical changes. Mech Ageing Dev 1980;14:435-42.

69. Gagliano N, Arosio B, Grizzi F, Masson S, Tagliabue J, Dioguardi N, Vergani C, Annoni G. Reduced collagenolytic activity of matrix metalloproteinases and development of liver fibrosis in the aging rat. Mech Ageing Dev 2002;123:413-25.

70. Lin CY, Ding HJ, Lin CC, Chen CC, Sun SS, Kao CH. Impact of age on FDG uptake in the liver on PET scan. Clin Imaging 2010;34:348-50.

71. Keramida G, Peters AM. FDG PET/CT of the nonmalignant liver in an increasingly obese world population. Clin Physiol Funct Imaging 2020;40:304-19.

72. Cao Y, Zhou K, Diao W, Long X, Tian F, Su M, Jia Z. Age-related changes of standardized uptake values in the blood pool and liver: a decade-long retrospective study of the outcomes of 2,526 subjects. Quant Imaging Med Surg 2021;11:95-106. 